\title{
Acute Lung Injury Regulation by Hyaluronan
}

\section{Patrick A. Singleton ${ }^{1,2 *}$ and Frances E. Lennon ${ }^{1}$}

${ }^{1}$ Department of Medicine, Section of Pulmonary and Critical Care, The University of Chicago, Chicago, IL 60637, USA

${ }^{2}$ Department of Anesthesia and Critical Care, Pritzker School of Medicine, The University of Chicago, Chicago, IL 60637, USA

\section{Summary}

Acute lung injury (ALI) and its more severe form, acute respiratory distress syndrome (ARDS), have high mortality rates with few treatment options. An important regulatory factor in the pathology observed in ALI/ARDS is a disruption of the pulmonary endothelial barrier which, in combination with epithelial barrier disruption, causes leakage of fluid, protein and cells into lung airspaces. Degradation of the glycosaminoglycan, hyaluronan (HA), is involved in reduction of the endothelial glycocalyx, disruption of endothelial cell-cell contacts and activation of HA binding proteins upregulated in ALI/ARDS which promote a loss of pulmonary vascular integrity. In contrast, exogenous administration of high molecular weight HA has been shown to be protective in several models of ALI. This review focuses on the dichotomous role of HA to both promote and inhibit ALI based on its size and the HA binding proteins present. Further, potential therapeutic applications of high molecular weight HA in treating ALI/ ARDS are discussed.

\section{Introduction}

Acute Lung Injury (ALI) and the more severe Acute Respiratory Distress Syndrome (ARDS) together constitute the leading cause of death in critical care patients. Current figures estimate the number of cases annually in the US as 200,000 with a mortality rate of $40 \%$ [1]. ALI and ARDS are characterized by rapid onset respiratory failure following a variety of direct or indirect insults to the parenchymal or vasculature of the lungs that induces inflammation and damages the cells of the alveolar-capillary membrane. This damage results in flooding of the alveolar air-spaces with protein-rich fluid leading to severe gas exchange abnormalities [2].

The American-European Consensus Conference (AECC) on ARDS in 1994 defined ALI as respiratory failure of acute onset with (a) $\mathrm{PaO}_{2} /$ $\mathrm{FiO}_{2}$ ratio of less that $300 \mathrm{mmHg}$, (b) bilateral infiltrates on frontal chest radiograph and (c) a pulmonary capillary wedge pressure of $18 \mathrm{mmHg}$ or less, or no evidence of left atrial hypertension. ARDS was defined identically except for a lower limiting value of less than $200 \mathrm{mmHg}$ for $\mathrm{PaO}_{2} / \mathrm{FiO}_{2}$. The arterial hypoxemia is caused by defective blood gas exchange due to accumulation of edema fluid in the distal airspaces of the lung. Carbon dioxide excretion is also abnormal which increases the respiratory rate, the minute ventilation rate and the work of breathing [3]. There are several clinical disorders associated with the development of ALI/ARDS including direct and indirect causes which are shown in (Table 1). The most common causes of ALI are pneumonia and sepsis. Many patients with ALI/ARDS also develop non-pulmonary organ failure such as cardiovascular or renal failure, abnormal liver function and haematologic abnormalities [3].

\begin{tabular}{|l|l|}
\hline \multicolumn{1}{|c|}{ Direct } & \multicolumn{1}{c|}{ Indirect } \\
\hline Pneumonia & Sepsis \\
\hline Aspiration of gastric contents & $\begin{array}{l}\text { Hemorrhagic shock/Transfusion-Relat- } \\
\text { ed Acute Lung Injury (TRALI) }\end{array}$ \\
\hline Breathing in smoke or toxic fumes & Injury (TRALI) \\
\hline Ventilator-induced injury & Major trauma or burn injury \\
\hline Near drowning & Acute pancreatitis \\
\hline Lung contusion & Adverse drug reaction \\
\hline $\begin{array}{l}\text { Ischemia/reperfusion injury (eg. lung } \\
\text { transplantation) }\end{array}$ & Fat embolism \\
\hline
\end{tabular}

Table 1: Causes of Acute Lung Injury.

The major causes of acute lung injury are listed based on whether they cause direct or indirect injury to the lung(5).

\section{Pathogenesis of ALI/ARDS}

During the initial phase of ALI, both the alveolar epithelium and capillary endothelium are damaged (either directly or indirectly). This disruption of the alveolar epithelial-endothelial barrier results in loss of barrier integrity and pulmonary edema, excessive neutrophil infiltration and release of pro-inflammatory cytokines and proteolytic enzymes. The increased neutrophil migration into the lung is an important feature, as ALI/ARDS is mostly an inflammatory disorder and neutrophils are believed to be the chief perpetrators of the inflammation [3]. Excessive neutrophil recruitment (to the alveolar and interstitial spaces) and activation (degranulation leading to release of proteases, reactive oxygen and nitrogen species, pro-inflammatory cytokines) contributes to the degradation of the basement membrane, apoptosis of alveolar type I and type II epithelial cells and increased permeability of the alveolar epithelial-endothelial barrier [1]. In addition to the neutrophils there is also emigration of macrophages which can amplify the injury by releasing inflammatory cytokines and pro-apoptotic molecules. This initial stage of ALI is often referred to as the exudative phase (1-4 days). The fibro-proliferative phase follows (days 4-14). The denuded epithelium is replaced by the formation of a proteinous hyaline membrane and alveolar spaces become filled with proliferating mesenchymal cells. At this stage the edema may start to resolve as proliferative alveolar type II epithelial cells begin to repair the barrier [4]. In some patients the edema and ALI will continue to resolve without fibrosis, however others will experience ongoing fibrosis with increased collagen and ECM deposition. An extended fibrotic response is associated with prolonged mechanical ventilation and increased mortality $[1,3,5]$.

*Corresponding author: Patrick A. Singleton, The University of Chicago Schoo of Medicine, 5841 South Maryland Avenue, MC 6076, I503C, Chicago, IL 60637 , USA, Tel: 773-702-2263; Fax: 773-702-4754; E-mail: psinglet@medicine.bsd. uchicago.edu

Received September 22, 2011; Accepted December 18, 2011; Published December 22, 2011

Citation: Singleton PA, Lennon FE (2011) Acute Lung Injury Regulation by Hyaluronan. J Aller Ther S4:003 doi:10.4172/2155-6121.S4-003

Copyright: (c) 2011 Singleton PA, et al. This is an open-access article distributed under the terms of the Creative Commons Attribution License, which permits unrestricted use, distribution, and reproduction in any medium, provided the original author and source are credited. 


\section{Hyaluronan Metabolism in the Lung}

Hyaluronan (HA) is composed of a linear repeat of disaccharide units consisting of D-glucuronic acid and $\mathrm{N}$-acetylglucosamine and is the major non-sulfated glycosaminoglycan in the lung [6,7]. HA is a dynamic molecule that can differentially promote or inhibit lung pathology based on its molecular weight and accessibility to various hyaluronan binding proteins. In the lung HA is mainly located in the peri-bronchial and inter-alveolar/peri-alveolar tissue and the adult lung contains approximately $160 \mathrm{mg}$ of HA [8]. The prevalent form of HA in vivo, high molecular weight HA (HMW-HA), exists with a molecular weight $>1$ million Da $[9,10]$. Structurally, HMW-HA exhibits a random coil structure that can expand in aqueous solution [11]. Aqueous HMW-HA is highly viscous and elastic, properties which contribute to its space filling and filtering functions. The levels of HA are regulated, in part, by the opposing activities of HA synthases and hyaluronidases, although HA may also be degraded by reactive oxygen species. Proinflammatory cytokines including TNF $\alpha$ IL-1 $\beta$ and LPS induce HA production in vitro [12]. Increased HA and its degradation products are observed in animal models of chronic obstructive pulmonary disease (COPD), ventilator-induced lung injury and bleomycin-induced lung injury [13,14]. Further, increased HA levels are observed in bronchoalveolar lavage (BAL) fluid and/or plasma from patients with lung disorders such as pulmonary fibrosis, COPD, allergic alveolitis, asthma, interstitial lung disease, sarcoidosis and idiopathic pulmonary arterial hypertension [15-21]. Airway epithelial cells also have increased HA production in response to tunicamycin-induced endoplasmic reticulum (ER) stress [22].

\section{Hyaluronan synthesis}

HA is synthesized by at least three membrane bound hyaluronan synthases (HAS1, HAS2 and HAS3) which are well conserved evolutionally despite being located on separate chromosomes [23]. HA synthesis is unusual compared to other glycosaminoglycans, as it is made at the inner face of the plasma membrane and not inside the Golgi. The growing HA molecule is extended at the reducing rather than the non-reducing terminus and, as the polymer grows, it is extruded into the extracellular space via the membrane spanning domains of the HAS $[24,25]$. Although hyaluronan synthases catalyse the same reaction, the three enzymes differ in a number of ways including in the $\mathrm{Km}$ values for their substrates (D-glucuronic acid and $\mathrm{N}$-acetylglucosamine) leading to differential rates of hyaluronan synthesis [26]. Secondly, HAS1 and HAS2 produce HA with a molecular weight $>500 \mathrm{kDa}$ and HAS3 produces a lower molecular weight (LMW) $\leq 500 \mathrm{kDa} H A$ [27]. These differences could account for the multiple types of HA matrix secreted by different cell types [9]. HAS expression is altered in a number of lung pathologies. Of particular relevance to acute lung injury is a study by Bai et al. which utilized a HAS knockout mouse to study the role of HAS3 and LMW-HA in ventilator-induced lung injury (VILI) [28]. While they observed an increase in LMW-HA and neutrophil infiltration in control animals at high ventilation tidal volumes, no increase in LMW-HA was detected in the HAS3 knockout animals and neutrophil infiltration was decreased [28]. This study and others indicate that HA synthesis has a role to play in lung pathology. HAS levels are variable depending on the pulmonary cell type and particular disease state. Although HA synthesis and total HA concentration, are important in regulating lung function, we must also consider the fact that HA degradation by hyaluronidase enzymes and reactive oxygen species can alter downstream signaling pathways that directly affect lung function.

\section{Hyaluronan degradation}

HA is degraded by hyaluronidases to produce lower molecular weight fragments $(<500 \mathrm{kDa})$ [29] .Six hyaluronidase genes encode HYAL-1,2,3,4, PHYAL1 (a pseudogene) and PH-20 [23]. A recent study by Hofinger et al, revealed that HA degradation by hyaluronidase enzymes may be $\mathrm{pH}$ dependent [30]. HA fragments are implicated in the progression of numerous lung diseases. HYAL-1 expression is increased in a rat model of monocrotaline-induced pulmonary hypertension leading to increased fragmentation of native HMW-HA and increased hyaluronidase activity in lung lysates [31]. In addition, HYAL-1 is increased in primary airway smooth muscle cells from asthmatic and COPD patients and these cells were found to degrade HMW-HA into $250 \mathrm{kDa}$ fragments compared to $700 \mathrm{kDa}$ for control cells [32]. A study by Dentener and colleagues found that HYAL-2 expression is also increased in the lungs of patients with COPD while HAS2 is decreased [16]. In contrast, HYAL-1 levels are decreased in the lungs of patients with idiopathic pulmonary arterial hypertension [20]. However, hyaluronidases are not the only HA-degrading moiety in the lung and other factors, including reactive oxygen species, can account for the presence and potential regulating activity of lower molecular weight HA $[33,34]$. Excess lung ROS can be generated from a variety of exogenous (particulate air pollution, cigarette smoke) and endogenous (activation of phagocytes, stimuli-induced NADPH oxidase, mitochondrial electron transport chain, xanthine oxidase, lipid peroxidation) sources [35-39]. Cigarette smoke generated ROS can degrade HA. Recently, it has been reported by Monzon at al. that ROS can regulate the expression of HYAL-2 in primary airway epithelial cells [33]. This combination of ROS and HYAL-2 expression stimulates the appearance of $\sim 75 \mathrm{kDa}$ HA fragments in lung secretions. These authors speculate that ROS exposure leads to an initial direct effect on HA degradation by ROS followed by sustained effects through the upregulation of HYAL enzymes [33]. Further, human airway epithelial cells exposed to xanthine/xanthine oxidase have HA fragment accumulation which is blocked by addition of superoxide dismutase (SOD) or catalase [40]. In addition, the extracellular SOD knockout mouse has increased LMW-HA in the lung compared to wild type controls [41]. A recent study by Eldridge et al reported an increase in HA fragmentation (at 4hrs) following pulmonary ischemia [ 42]. However they could not detect any increase in hyaluronidase activity and the fragmentation was reduced in animals given NAC anti-oxidant pre-treatment prior to left pulmonary artery ligation (LPAL). Based on these findings and their previous reports of increased ROS production following LPAL they concluded that that ROS generation contributed to HA fragmentation in the lung [42].

\section{Hyaluronan and the endothelial glycocalyx}

Hyaluronan is a major component of the endothelial glycocalyx, a negatively charged mesh of membrane glycoproteins, proteoglycans and glycosaminoglycans located on the luminal side of the endothelium in all vessels [43-45]. The glycocalyx is currently the focus of much research and is believed to have a number of important vasculoprotective functions in vivo, including a) regulation of vascular permeability (to water and proteins), b) modulation of leukocyte rolling and adhesion, c) transduction of shear stress leading to NO release and d) inhibition of coagulation [46-50]. The majority of the glycocalyx is located in the peripheral vasculature and most studies have focused on the glycocalyx in the microvasculature [51]. The glycocalyx acts as a molecular "sieve", retaining proteins in the flowing blood which establishes an oncotic gradient across the glycocalyx itself, limiting the net outflow of filtrate from the blood to the interstitial space [52]. Degradation of 
the glycocalyx leads to mycocardial edema in perfused rat hearts [53]. Although the role of the glycocalyx in maintaining fluid balance in the lung has not been extensively studied, a number of reports indicate that it does have a key role to play in homeostasis. An early report by Schneeberger and Hamelin in the mid 80's indicated that disruption of albumin binding by the glycocalyx (and perhaps disruption of the glycocalyx itself) increased lung endothelial permeability to ferritin [54]. A number of other ALI precipitating disorders have been shown to disrupt the endothelial glycocalyx and increase free HA in the plasma [13]. Glycocalyx disruption has been reported in sepsis, after major surgery, hemorrhagic shock, ischemia/reperfusion and following LPS administration in animal models [13,55-60]. Using an animal models, Kozar et al. have shown that the endothelial glycocalyx was virtually ablated by hemorrhagic shock, a known cause of acute lung injury [57]. Restoration of the glycocalyx by plasma resuscitation led to decreased lung injury as measured by alveolar wall thickness, capillary congestion and cellularity [57]. These results would suggest that the glycocalyx and HA has an important role to play in maintaining endothelial barrier function in the lung and shedding of the HA glycocalyx could be a major factor contributing to the pathogenesis of ALI/ARDS.

\section{Hyaluronan signaling}

HA itself can directly influence cell behavior through binding cell surface receptors. In general terms HMW HA is regarded as mediating the homeostatic functions of HA, including tissue hydration, lubrication and acting as a support matrix for cells. However HMW HA may also be actively involved in regulating cell proliferation and differentiation. It has long been shown that HA molecular weight is an important factor regulating its signaling activities. HMW-HA can mediate EMT during heart valve formation via ErbB2, [61] induce COX-2 expression in endothelial cells via CD44, and enhance endothelial barrier function in the lung via CD44, the S1P1 receptor and Akt and Rac signaling [6265]. Following its degradation, however the signaling properties of HA are altered. LMW-HA is generally considered to be more "biologically active" than the native HMW HA. LMW-HA has been show to decrease endothelial barrier function, stimulate angiogenesis, cell migration and immune cell recruitment and induce expression of a host of inflammatory mediators in alveolar macrophages including MIP-1 $\alpha$, RANTES, Mig, IP-10 and PAI-1 via CD44, TLR2 and TLR4 [64,6670]. Therefore, the effects of HA are wide ranging and complex and are dependent, not only on concentration and molecular weight but also on the specific receptors expressed and cell type involved. In this review we have undertaken to examine the role of HA, and HA interacting proteins, as they apply to the spectrum of acute lung injury pathologies.

\section{Hyaluronan binding proteins}

Hyaluronan and its degradation products bind to a variety of hyaluronan binding proteins that exist in diverse locales including the blood, extracellular matrix, cell plasma membrane, cytosol and nucleus. The differential activities of HA are regulated in the lung, in part, through interactions with HA binding proteins including CD44, HABP2, TLR4/TLR2 and RHAMM. The role of these proteins in ALI/ ARDS and is discussed below (Table 2). As ALI has many etiologies a number of different animal models exist based on the clinical disorders associated with ALI/ARDS. The most widely used models include mechanical ventilation, administration of LPS and live bacteria, hyperoxia and bleomycin administration. A more complete review of the different animal models of ALI [71].

\begin{tabular}{|l|l|l|}
\hline HA Binding Protein & Associated Lung Pathology & Refs \\
\hline \multirow{5}{*}{ CD44 } & LPS-induced lung injury & $(65,85)$ \\
& Non-infectious lung injury & $(81,83)$ \\
& Pneumonia & $(89)$ \\
& Pulmonary Vascular Leakiness & $(65,86)$ \\
& Hyperoxia & $(91)$ \\
\hline HABP2 & LPS-induced lung injury & $(101)$ \\
& Ventilator-induced lung injury & $(101)$ \\
& ARDS & $(102)$ \\
& Pulmonary Vascular Leakiness & $(101)$ \\
\hline TLR4/TLR2 & LPS-induced lung injury & $(8)$ \\
& Non-infectious lung injury & $(69,92)$ \\
& Ventilator-induced lung injury & $(110)$ \\
& Ozone-induced lung injury & $(121,130)$ \\
\hline RHAMM & Hyperoxia & $(131)$ \\
\hline
\end{tabular}

Table 2: Hyaluronan binding proteins and their associated lung pathologies Table summarizing the HA binding proteins discussed in this review, their association with various ALI-related lung pathologies and corresponding references.

\section{CD44}

CD44 is a type 1 transmembrane glycoprotein expressed in a variety of lung cell types including pulmonary epithelial, fibroblast, endothelial and hematopoietic cells [72-75]. There are several CD44 isoforms, resulting from alternative exon splicing often occuring between exons 5 and 15 leading to a tandem insertion of one or more variant exons (v1-v10, or exons 6 through exons 14) within the membrane proximal region of the extracellular domain. CD44 expression can be regulated in response to inflammatory stimuli such as LPS and cytokines including IL-1 $\beta$ and TNF- $\alpha$ and growth factors such as bFGF and VEGF [76-78]. The extracellular domain of CD44 contains clusters of conserved basic residues which are part of a HA-binding Link module common to HA binding proteins [75]. The cytoplasmic domain of CD44 functions to recruit regulatory proteins to the cell membrane and initiate HAmediated intracellular signaling. Some examples of signaling pathways and molecules activated by HA binding of CD44 include Rac activation leading to lamellipodia formation, ERM and merlin proteins, Src and ROCK $[64,73,79,80]$. The importance of CD44 in the lung has been demonstrated through the use of the CD44 knockout mouse in multiple models of lung disease including inflammation, vascular leak syndromes and non-infectious lung diseases which are discussed below.

\section{CD44 and non-infectious lung injury}

Intratracheal administration of bleomycin is an important model for non-infectious lung injury and fibrosis [71]. Bleomycin causes an acute pulmonary epithelial cell injury and inflammatory response which later subsides and develops into lung fibrosis [71]. Lung CD44 expression is increased in the initial acute inflammatory response along with a transient increase in HA concentration in the lung interstitium [81]. In the CD44 knockout mouse, the bleomycin-induced acute inflammatory response persists leading to excess immune cell recruitment to the lungs, excess inflammatory cytokine production, decreased TGF $\alpha$ activation, progressive HA fragment $(<500 \mathrm{kDa})$ accumulation and ultimately death [82]. In humans, CD44 is up-regulated in the lungs of patients with acute alveolar fibrosis. Treatment of lung mesenchymal cells isolated from these patients with anti-CD44 antibody attenuated migration and invasion into a fibrin matrix [83]. This study did not examine HA localization, concentration or molecular weight in the lungs of these patients. As the principal ligand for CD44, any alterations in HA size or concentration could greatly influence CD44 signaling. 


\section{CD44 and lipopolysaccharide (LPS)-induced lung injury}

LPS is an potent endotoxin from Gram-negative bacteria that, when administered intratracheally, produces an inflammatory reaction characterized by disruption of epithelial/endothelial barriers and leakage of fluid, protein and immune cells into lung airspaces [84]. Recently, it has been demonstrated by our laboratory and others that CD44 knockout mice have increased bronchoalveolar lavage (BAL) protein and HA concentration and exaggerated inflammatory cell recruitment of both macrophages and neutrophils with LPS-induced lung injury $[85,86]$. CD44 knockout mice also have increased NF$\mathrm{\kappa B}$ nuclear translocation and cytokine production. In this model of intratracheal administration of LPS, it appears that CD44 acts as a negative regulator to limit the in vivo response to LPS and prevent excessive tissue damage [86]. However, a report from Hollingsworth et al. appears to challenge this, as they observed decreased macrophage infiltration and chemokine secretion in their model of aerosolized LPSinduced inflammation. These differences are likely accounted for by the different modes of delivery (intratracheal versus aerosolized) and lower LPS concentration leading to a milder inflammatory response and faster resolution. One common finding in all of these studies is the increased concentrations of HA in the BAL fluid of CD44 knockout mice.

\section{CD44 and pneumonia}

Pneumonia is a disease characterized by inflammation of the parenchyma of the lung and alveolar edema and is the sixth leading cause of death in America $[87,88]$. In animal models of pneumonia using live Escherichia coli and Streptococcus pneumoniae bacteria, CD44-deficient mice had increased expression of the neutrophil chemoattractant proteins, KC and MIP-2 $[9,82]$. However, it was only in the E. coli model of pneumonia where CD44-deficient mice exhibited increased neutrophil migration and edema formation [82]. Patients with eosinophilic pneumonia have increased levels of HA and soluble CD44 in BAL fluid and increased numbers of CD44 expressing eosinophils in BAL [89]. The increase in CD44 is reported to be due to a local increase in IL-5 production in the lung [89]. Unfortunately, the authors in this study did not examine the size of HA in the BAL or its effect on other cell types such as neutrophils or macrophages.

\section{CD44 and hyperoxia}

Hyperoxia is often used as a treatment to increase tissue oxygenation during ALI but can also lead to further lung damage, even in healthy tissue [90]. A recent study by Van der Windt et al. reports that CD44 has a protective role in hyperoxia induced lung injury [91]. The report indicates that CD44 knockout mice have increased mortalilty compared to WT animals and exhibit higher levels of necrosis in their lungs, particularly the bronchiolar tissue. Although both groups of mice have increased numbers of neutrophils in BALF after $24 \mathrm{hrs}$ of hyperoxia, CD44 knockout mice have significantly higher numbers of neutrophils compared to control mice [91]. CD44 knockout mice also have increased levels of HA in BAL fluid but unfortunately the size of this HA was not determined. No changes were observed in the levels of osteopontin, another CD44 ligand [91]. This data suggests that CD44 is protective for the lung epithelium during hyperoxia by limiting the neutrophil response and preventing HA buildup in the lung. The role of other HA binding receptors, such as TLR4 which may modulate the functions of CD44 in the lung, should also be considered in this context considering TLR4 knockout mice are more susceptiable to hyperoxia injury [92].

\section{CD44 and pulmonary vascular leakiness}

Endothelial cells (EC) make up 30\% of lung tissue and disruption of the EC barrier is a critical feature of inflammation as well as an important contributing factor to ALI[21,93]. We have demonstrated that human pulmonary EC express the CD44 isoforms, CD44s (standard form) and CD44v10 [64]. In vitro models of pulmonary EC barrier function indicate that HMW-HA $(\sim 1$ million $\mathrm{Da})$ activates CD44s signaling and promotes barrier enhancement through its interaction with the S1P1 receptor and activation of Rac1 signaling leading to cytoskeletal reorganization while HA fragments $(\sim 2.5 \mathrm{KDa})$ activate CD44v10 signaling and induce barrier disruption via $\mathrm{S}_{1} \mathrm{P}_{3}$ and Rho signaling [64]. In animal models, pulmonary vascular leak caused by intraperitoneal administration of IL-2 is attenuated in CD44 knockout mice and by CD44 antibody blockage $[94,95]$.

\section{HABP2}

Hyaluronic acid binding protein 2 (HABP2), also called FSAP (factor VII activating protease), is a HA binding extracellular serine protease involved in the extrinsic pathway of blood coagulation via activation of factor VII and fibrinolysis via activation of pro-urokinase type plasminogen activator (pro-uPA) [96-99]. It is expressed as a single amino acid chain proenzyme that undergoes autocatalytic cleavage upon binding of a ligand [100]. The mature enzyme consists of trypsinlike catalytic domain, linked via disulfide bond to the kringle domain and three epidermal growth factor (EGF)-like domains. The second and third EGF-like domains form the polyanion binding domain (PABD) [99].

\section{HABP2 and lung injury with pulmonary vascular leakiness}

Intratracheal LPS administration produces an inflammatory reaction characterized by disruption of epithelial and endothelial cellular barriers with leakage of fluid, protein and immune cells into lung airspaces [84]. Although mainly produced in the liver, we and others have demonstrated that the pulmonary endothelium expresses HABP2 which is upregulated with lung injury [101,102]. HABP2 promotes LPS- and HA fragment $(\sim 2,500 \mathrm{Da})$-mediated human pulmonary endothelial cell barrier disruption through a mechanism that involves protease-activated receptors (PAR) and inhibits HMWHA-mediated endothelial barrier protection in vitro [101]. We determined the contribution of vascular HABP2 to lung injury in mice by inhibiting HABP2 through intravenous administration of HABP2 siRNA and observed attenuation of LPS-induced ALI. In addition, vascular inhibition of HABP2 expression attenuates pulmonary vascular hyper-permeability, in a mouse model of ventilator-induced lung injury, demonstrating an important role of HABP2 in the development of ALI [101]

\section{HABP2 and acute respiratory distress syndrome (ARDS)}

HABP2 levels and activity are increased in the BAL fluid of mechanically ventilated patients with early ARDS compared with patients with cardiogenic pulmonary edema or healthy controls [102] In patients who died from ARDS, immunohistochemical analysis of excised lungs revealed HABP2 levels are increased in alvealor macrophages, bronchial epithelial and pulmonary endothelial cells [102]. This suggests a role for HABP2 in the pathogenesis of ARDS.

\section{TLR4/TLR2}

Toll-like receptors (TLR) sense exogenous and endogenous dangerassociated molecular motifs and produce inflammatory responses [103]. Structurally, TLR contain an extracellular leucine-rich repeat 
domain (LRR) and a cytosolic Toll/IL-1 receptor homology domain (TIR) [103]. TLR4 and TLR2 are the principal receptors for bacterial cell wall components. TLR4 is the major receptor for LPS and can also bind HA, HMGB1, oxidized lipoproteins and oxidized phospholipids since these molecules contain features of "pathogen-associated molecular patterns (PAMPs)" [104]. TLR2 mediates cell responses to lipoproteins and lipoteichoic acid from Gram-positive bacteria and mycobbacteria [105]. Following ligand binding the TLR adaptor molecule MyD88 is recruited to the signaling complex. This adaptor then promotes association with other downstream signaling molecules including IRAK, TRAF and TAK-1 which ultimately results in activation and nuclear translocation of NF- $\mathrm{KB}$. TLRs are also reported to have a role in regulating non-infectious lung injury [106]. Interestingly, CD44 and TLR4 are shown to be physically associated in a signaling complex following exposure to HA [107].

\section{TLR4 and lipopolysaccharide (LPS)-induced lung injury}

Intratracheal administration of LPS induces a lung inflammatory reaction. Inhibition of TLR4 in animal models protects against LPSinduced lung injury [108-110]. TLR4 knockout animals show decreased neutrophil infiltration and have decreased levels of TNF- $\alpha$, IL- $1 \beta$, and IL-6 [111]. A TLR4 blocking antibody is reported to decrease lung inflammation in a rabbit model of LPS-induced injury in mechanically ventilated animals [110]. In humans, TLR4 loss-of-function mutations attenuate inhaled LPS-induced lung injury [112]. Interestingly, CD44 deficient mice have decreased expression of negative regulators of TLR including IL-1R-associated kinase M (IRAK-M), Toll-interacting protein (Tollip) and TNF $\alpha$-induced protein 3 (A20) [8]. Muto et al. go one step further in their model of the septic response to LPS by showing that pretreatment with HMW-HA (with a range of molecular weights up to $500 \mathrm{kDa}$ ) is protective against LPS induced shock [113]. CD44 knockout mice are not protected in this model [113]. This indicates that CD44 and HA play an active role in regulating TLR4 signaling events. Alveolar macrophages isolated from both control treated and CD44 knockout mice have differences in TNF- $\alpha$ and IL-6 expression, with HA pretreated control macrophages showing decreased expression following LPS exposure. HA treated macrophages also have increased expression of the TLR4 negative regulator TNF- $\alpha$-induced protein 3/ A20 [113].

\section{TLR4/TLR2 and non-infectious lung injury}

Intratracheal bleomycin treatment causes enhanced pulmonary epithelial cell apoptosis, exaggerated lung injury and impaired inflammatory cell migration in the double TLR2/TLR4 knockout mouse, results similar to blocking HA with the Pep-1 peptide in bleomycin-treated wildtype mice [69]. In addition, induction of inflammatory cytokine expression by HA fragments $(\sim 135 \mathrm{kDa})$ is completely blocked in double TLR2/TLR4 knockout mouse peritoneal macrophages and reduced in TLR4 knockouts [69]. Using a model of lung inflammation induced by LMW-HA $(200 \mathrm{kDa})$ administered directly to the trachea, Zhao et al. report that TLR4 acts as a negative regulator [92]. The authors found an increase in neutrophilic infiltration and red blood cells in BAL fluid of TLR4 knockout animals. They report TLR deficiency essentially increases LMW-HA induced lung injury due to an imbalance in the ratio of pro- and anti-inflammatory mediators in the lungs of TLR4 knockout animals. TLR4 knockouts had increased IL-1 $\beta$, MIP-2, TNF- $\alpha$, and IL-6 levels in BAL fluid following LMWHA administration, and can be rescued by pre-treatment with IL-1RA [92]. These results are somewhat at odds with those reported by Jiang et al. where TLR4 knockout reduced MIP-2 expression by peritoneal macrophages [69]. This difference may be accounted for by the cell specific effects of TLR4 and HA. Scheibner et al. report that TLR2 but not TLR3 or TLR5 (TLR4 was not examined) is required for peritoneal macrophage activation and MIP-1 $\alpha$ expression by LMW-HA (200 $\mathrm{kDa})$, which can be blocked by HMW-HA $(6,000 \mathrm{kDa})[114]$.

\section{RHAMM}

The receptor for HA-mediated motility (RHAMM) is found in diverse cellular locales including the cell surface, cytosol, mitochondria and nucleus(75). RHAMM activates ERK1/2 and regulates mitoticspindle integrity. RHAMM is alternatively spliced like CD44 and these two HA binding proteins are often co-expressed in pulmonary cells [72]. In some cases, RHAMM may compensate for CD44 function [72].

\section{RHAMM and non-infectious lung injury}

As stated previously, one common animal model for non-infectious lung injury is intratracheal administration of bleomycin. RHAMM expression is increased in lung macrophages with bleomycin treatment. Intraperitoneal injection of anti-RHAMM antibody attenuates bleomycin-induced lung macrophage recruitment and reduction of alveolar septae thickening and early indications of lung fibrosis [115].

\section{Therapeutic Potential of Hyaluronan}

Although HMW-HA ( $\geq 1$ million $\mathrm{Da}$ ) is produced endogenously and is an integral component of the extracellular matrix, synovial fluid and vitreous humor, recent attention has been focused on the use of exogenously administered HMW-HA in a variety of diseases including lung disease [116,117]. In vitro, exogenous administration of HMWHA inhibits ROS, nitrotyrosine and inflammatory cytokine production as well as promotes immune tolerance [118-120]. In addition, excess production of endogenous HMW-HA in mice overexpressing HAS2 in airway epithelia protects against bleomycin-induced lung injury and ozone-induced airway hyperresponsiveness $[69,121]$.

As discussed earlier HA forms a major part of the vascular glycocalyx [43]. Loss or disruption of the glycocalyx leading to increased vascular permeability and edema and may be a contributing factor in ALI. Repair of the glycocalyx and restoration of vascular barrier function could potentially be beneficial in the treatment of ALI. Previous studies have shown restoration of the glycocalyx by plasma resuscitation in animal models of hemorrhagic shock [57]. Other studies have shown that perfusion of HA can restore the glycocalyx following degradation with by hyaluronidase or in response to ischemia/reperfusion injury $[122,123]$.

\section{Exogenous HMW-HA and lipopolysaccharide (LPS)-induced lung injury}

We have recently demonstrated that intravenous administration of HMW-HA ( 1 million Da) four hours after intratracheal administration of LPS provides protection against lung injury in mice [86]. This is in agreement with Nadkarni et al. who demonstrated pretreatment of hamsters with aerosolized HMW-HA protects against endotoxin-induced lung injury [124]. Interestingly, these authors noted that treatment with aerosolized HMW-HA after endotoxin treatment actually enhanced lung inflammation indicating the timing and route of administration are important determinants of HMW-HA's effectiveness. 


\section{Exogenous HMW-HA and sepsis/ventilator-induced lung injury}

Intraperitoneal administration of HMW-HA (1.6 million Da) 18 hours prior mechanically ventilation with a low tidal volume (7 $\mathrm{ml} / \mathrm{kg}$ ) and carotid artery administration of LPS (to induce sepsis) protects rats from lung injury [125]. In these same studies, intravenous administration of HMW-HA at the same time as initiation of ventilation also protected from lung injury [125]. Interestingly, the use of $35 \mathrm{kDa}$ HA showed partial protection in these models, but to a lesser extent that HMW-HA. Our laboratory has also demonstrated intravenous administration of HMW-HA protects from ventilator-induced lung injury in mice [21].

\section{Exogeneous LMW-HA and cigarette smoke-induced lung injury}

Smoking is a well known cause of lung injury which can lead to the development of emphysema and chronic pulmonary obstructive disease (COPD). Cigarette-smoke is believed to induce an imbalance in the protease-antiprotease levels in the lung [126]. This imbalance, which develops due to increased inflammatory cell recruitment, activation and release of protease enzymes (including elastase), leads to proteolytic breakdown of the extracellular matrix and the elastin fibers. Breakdown of the elastin fibers can lead to alveolar distention and rupture a prominent feature of emphysema and COPD [127]. Although HA itself does not inhibit protease activity, studies by Cantor and Turino have shown that it may be protective against elastin fiber breakdown. They have shown that aerosolized LMW HA $(150 \mathrm{kDa})$ binds or closely associates with the elastin fibers and may physically protect them from degradation by proteases $[127,128]$. A clinical trial is currently underway to determine the use of hyaluronan as a treatment in COPD.

\section{Concluding Remarks}

ALI and ARDS affects approximately 200,000 people annually in the US alone with a mortality rate of up to $40 \%$. Although there are numerous clinical disorders associated with the development of ALI/ ARDS it is regarded as an inflammatory condition which damages the lung epithelium and endothelium leading to an increase in permeability and pulmonary edema. Despite what is currently known about the causes and pathogenesis of ALI/ARDS there are no specific therapies available. Current treatment strategies are focused on mechanical ventilation and fluid management [129]. New therapies and treatment strategies are therefore urgently needed. The role of $\mathrm{HA}$ and its degradation products in the lung is complex. HA and HA binding proteins are involved in a number of processes including inflammation and barrier function. The expression of HA binding proteins is upregulated in many ALI models along with increased HA turnover by hyaluronidase enzymes and reactive oxygen species. The HA metabolic pathway is therefore an attractive and novel therapeutic target. Preliminary results have already indicated that HMW HA can be used to repair the damaged vascular glycocalyx and also to protect against LPS and ventilator induced lung injury, while LMW HA may protect against proteolytic damage in emphysema. More research is needed to fully understand the complexities of HA in acute lung injury and how signaling by multiple HA binding proteins integrate together in the lung and are altered in response to injury. However from the reports published thus far hyaluronan may offer a therapeutic benefit as a treatment in acute lung injury.

\section{Grants}

Dr. Patrick A. Singleton was supported in part by the American Heart Association National Scientist Development Grant 0730277N, the American Lung Association National Biomedical Research Grant RG-75229-N and NIH NHLBI grant RO1-HL 095723.

\section{References}

1. Johnson ER, Matthay MA (2010) Acute lung injury: epidemiology, pathogenesis, and treatment. J Aerosol Med Pulm Drug Deliv 23: 243-252.

2. Raghavendran K, Napolitano LM (2011) Definition of ALI/ARDS. Crit Care Clin 27: 429-437.

3. Matthay MA, Zemans RL, (2011) The acute respiratory distress syndrome pathogenesis and treatment. Annu Rev Pathol 6: 147-163.

4. Cross LJ, Matthay MA (2011) Biomarkers in acute lung injury: insights into the pathogenesis of acute lung injury. Crit Care Clin 27: 355-377.

5. Deng JC, Standiford TJ (2011) Growth Factors and Cytokines in Acute Lung Injury, Comprehensive Physiology 1: 24.

6. Almond A (2007) Hyaluronan. Cell Mol Life Sci 64: 1591-1596.

7. Genasetti A, Vigetti D, Viola M, Karousou E, Moretto P, et al. (2008) Hyaluronan and human endothelial cell behavior. Connect Tissue Res 49: 120-123.

8. Liang J, Jiang D, Griffith J, Yu S, Fan J, et al. (2007) CD44 is a negative regulator of acute pulmonary inflammation and lipopolysaccharide-TLR signaling in mouse macrophages. J Immunol 178: 2469-2475.

9. Wang A, de la Motte C, Lauer M, Hascall V (2011) Hyaluronan matrices in pathobiological processes. FEBS J 278: 1412-1418.

10. Heldin P, Karousou E, Bernert B, Porsch H, Nishitsuka K, et al. (2008) Importance of hyaluronan-CD44 interactions in inflammation and tumorigenesis. Connect Tissue Res 49: 215-218.

11. Scott JE, Heatley $F$ (2002) Biological properties of hyaluronan in aqueous solution are controlled and sequestered by reversible tertiary structures, defined by NMR spectroscopy. Biomacromolecules 3: 547-553.

12. Mohamadzadeh $M$, DeGrendele $H$, Arizpe H, Estess $P$, Siegelman $M(1998)$ Proinflammatory stimuli regulate endothelial hyaluronan expression and CD44/ HA-dependent primary adhesion. J Clin Invest 101: 97-108.

13. Kredel M, Muellenbach RM, Brock RW, Wilckens HH, Brederlau J, et al. (2007) Liver dysfunction after lung recruitment manoeuvres during pressure-controlled ventilation in experimental acute respiratory distress. Crit Care 11: R13.

14. Zhao HW, Lü CJ, Yu RJ, Hou XM (1999) An increase in hyaluronan by lung fibroblasts: a biomarker for intensity and activity of interstitial pulmonary fibrosis?. Respirology 4:131-138.

15. Bensadoun ES, Burke AK, Hogg JC, Roberts CR (1996) Proteoglycan deposition in pulmonary fibrosis. Am J Respir Crit Care Med 154: 1819-1828.

16. Dentener MA, Vernooy JH, Hendriks S, Wouters EF (2005) Enhanced levels of hyaluronan in lungs of patients with COPD: relationship with lung function and local inflammation. Thorax 60: 114-119.

17. Zhu Z, Lee CG, Zheng T, Chupp G, Wang J, et al. (2001) Airway inflammation and remodeling in asthma. Lessons from interleukin 11 and interleukin 13 transgenic mice. Am J Respir Crit Care Med 164: S67-70.

18. Cantin AM, Larivée P, Martel M, Bégin R (1992) Hyaluronan (hyaluronic acid) in lung lavage of asbestos-exposed humans and sheep. Lung 170: 211-220.

19. Milman N, Kristensen MS, Bentsen K, Grode G, Frederiksen J (1995) Hyaluronan and procollagen type III aminoterminal peptide in serum and bronchoalveolar lavage fluid in patients with pulmonary sarcoidosis. Sarcoidosis 12: 38-41.

20. Papakonstantinou E, Kouri FM, Karakiulakis G, Klagas I, Eickelberg O (2008) Increased hyaluronic acid content in idiopathic pulmonary arterial hypertension. Eur Respir J 32: 1504-1512.

21. Lennon FE, Singleton PA (2011) Role of hyaluronan and hyaluronan-binding proteins in lung pathobiology. Am J Physiol Lung Cell Mol Physiol 301: L137147.

22. Lauer ME, Erzurum SC, Mukhopadhyay D, Vasanji A, Drazba J, et al. (2008) Differentiated murine airway epithelial cells synthesize a leukocyte-adhesive hyaluronan matrix in response to endoplasmic reticulum stress. J Biol Chem 283: 26283-26296. 
23. Csoka AB, Frost GI, Stern $R$ (2001) The six hyaluronidase-like genes in the human and mouse genomes. Matrix Biol 20: 499-508.

24. Toole BP (2000) Hyaluronan is not just a goo! J Clin Invest 106: 335-336.

25. Toole BP (2004) Hyaluronan: from extracellular glue to pericellular cue. Nat Rev Cancer 4: 528-539.

26. Itano N, Kimata K (2002) Mammalian hyaluronan synthases. IUBMB Life 54: 195-199.

27. Weigel PH, DeAngelis PL (2007) Hyaluronan synthases: a decade-plus of novel glycosyltransferases. J Biol Chem 282: 36777-36781.

28. Bai KJ, Spicer AP, Mascarenhas MM, Yu L, Ochoa CD, et al. (2005) The role of hyaluronan synthase 3 in ventilator-induced lung injury. Am J Respir Crit Care Med 172: 92-98.

29. Girish KS, Kemparaju K (2007) The magic glue hyaluronan and its eraser hyaluronidase: a biological overview. Life Sci 80: 1921-1943.

30. Hofinger ES, Hoechstetter J, Oettl M, Bernhardt G, Buschauer A (2008) Isoenzyme-specific differences in the degradation of hyaluronic acid by mammalian-type hyaluronidases. Glycoconj J 25: 101-109.

31. Ormiston ML, Slaughter GR, Deng Y, Stewart DJ, Courtman DW (2010) The enzymatic degradation of hyaluronan is associated with disease progression in experimental pulmonary hypertension. Am J Physiol Lung Cell Mol Physio 298: L148-157.

32. Klagas I, Goulet S, Karakiulakis G, Zhong J, Baraket M, et al. (2009) Decreased hyaluronan in airway smooth muscle cells from patients with asthma and COPD. Eur Respir J 34: 616-628.

33. Monzon ME, Fregien N, Schmid N, Falcon NS, Campos M, et al. (2010) Reactive oxygen species and hyaluronidase 2 regulate airway epithelial hyaluronan fragmentation, J Biol Chem 285: 26126-26134.

34. Soltés L, Mendichi R, Kogan G, Schiller J, Stankovska M, etal. (2006)Degradative action of reactive oxygen species on hyaluronan. Biomacromolecules 7: 659 668

35. Cave AC, Brewer AC, Narayanapanicker A, Ray R, Grieve DJ, et al. (2006) NADPH oxidases in cardiovascular health and disease. Antioxid Redox Signal 8: 691-728.

36. Circu ML, Aw TY (2010) Reactive oxygen species, cellular redox systems, and apoptosis. Free Radic Biol Med 48: 749-762.

37. Forman HJ, Maiorino M, Ursini F (2010)Signaling functions of reactive oxygen species. Biochemistry 49: 835-842.

38. Ray R, Shah AM (2005) NADPH oxidase and endothelial cell function. Clin Sc (Lond) 109: 217-226.

39. Ushio-Fukai M (2006) Localizing NADPH oxidase-derived ROS. Sci STKE 2006: re8

40. Manzanares D, Monzon ME, Savani RC, Salathe M (2007) Apical oxidative hyaluronan degradation stimulates airway ciliary beating via RHAMM and RON. Am J Respir Cell Mol Biol 37: 160-168.

41. Gao F, Koenitzer JR, Tobolewski JM, Jiang D, Liang J, et al. (2008) Extracellular superoxide dismutase inhibits inflammation by preventing oxidative fragmentation of hyaluronan. J Biol Chem 283: 6058-6066.

42. Eldridge L, Moldobaeva A, Wagner EM (2011) Increased Hyaluronan Fragmentation During Pulmonary Ischemia. Am J Physiol Lung Cell Mol Physiol.

43. Reitsma S, Slaaf DW, Vink $H$, van Zandvoort MA, oude Egbrink MG, et al. (2007) The endothelial glycocalyx: composition, functions, and visualization. Pflugers Arch 454:345-359

44. Wheeler-Jones CP, Farrar CE, Pitsillides AA (2010) Targeting hyaluronan of the endothelial glycocalyx for therapeutic intervention. Curr Opin Investig Drugs 11: 997-1006.

45. Becker BF, Chappell D, Bruegger D, Annecke T, Jacob M (2010) Therapeutic strategies targeting the endothelial glycocalyx: acute deficits, but great potential. Cardiovasc Res 87: 300-310.

46. Nieuwdorp M, Meuwese MC, Vink H, Hoekstra JB, Kastelein JJ (2005) The endothelial glycocalyx: a potential barrier between health and vascular disease. Curr Opin Lipidol 16: 507-511.
47. Nieuwdorp M, van Haeften TW, Gouverneur MC, Mooij HL, van Lieshout MH, et al. (2006) Loss of endothelial glycocalyx during acute hyperglycemia coincides with endothelial dysfunction and coagulation activation in vivo. Diabetes 55 480-486.

48. Perrin RM, Harper SJ, Bates DO (2007) A role for the endothelial glycocalyx in regulating microvascular permeability in diabetes mellitus. Cell Biochem Biophys 49: 65-72.

49. Chappell D, Westphal M, Jacob M (2009) The impact of the glycocalyx on microcirculatory oxygen distribution in critical illness. Curr Opin Anaesthesiol 22: $155-162$

50. Drake-Holland AJ, Noble MI (2009) The important new drug target in cardiovascular medicine--the vascular glycocalyx. Cardiovasc Hematol Disord Drug Targets 9: 118-123

51. Gao L, Lipowsky HH (2010) Composition of the endothelial glycocalyx and its relation to its thickness and diffusion of small solutes. Microvasc Res 80: 394 401

52. Curry FR (2005) Microvascular solute and water transport. Microcirculation 12 $17-31$.

53. van den Berg BM, Vink H, Spaan JA (2003) The endothelial glycocalyx protects against myocardial edema. Circ Res 92: 592-594.

54. Schneeberger EE, Hamelin M (1984) Interaction of serum proteins with lung endothelial glycocalyx: its effect on endothelial permeability, Am J Physiol 247 H206-217.

55. Annecke T, Fischer J, Hartmann H, Tschoep J, Rehm M, et al. (2011) Shedding of the coronary endothelial glycocalyx: effects of hypoxia/reoxygenation vs ischaemia/reperfusion. $\mathrm{Br} \mathrm{J}$ Anaesth 107: 679-686.

56. Henrich M, Gruss M, Weigand MA (2010) Sepsis-induced degradation of endothelial glycocalix, ScientificWorldJournal 10: 917-923.

57. Kozar RA, Peng Z, Zhang R, Holcomb JB, Pati S, et al. (2011) Plasma restoration of endothelial glycocalyx in a rodent model of hemorrhagic shock Anesth Analg 112: 1289-1295.

58. Marechal X, Favory R, Joulin O, Montaigne D, Hassoun S, et al. (2008) Endothelial glycocalyx damage during endotoxemia coincides with microcirculatory dysfunction and vascular oxidative stress, Shock 29: 572-576.

59. Mulivor AW, Lipowsky HH (2004) Inflammation- and ischemia-induced shedding of venular glycocalyx, Am J Physiol Heart Circ Physiol 286: H1672-1680.

60. Rehm M, Bruegger D, Christ F, Conzen P, Thiel M, et al. (2007) Shedding of the endothelial glycocalyx in patients undergoing major vascular surgery with global and regional ischemia Circulation 116: 1896-1906.

61. Camenisch TD, Spicer AP, Brehm-Gibson T, Biesterfeldt J, Augustine ML, et al. (2000) Disruption of hyaluronan synthase-2 abrogates normal cardiac morphogenesis and hyaluronan-mediated transformation of epithelium to mesenchyme. J Clin Invest $106: 349-360$

62. Murphy JF, Lennon F, Steele C, Kelleher D, Fitzgerald D, et al. (2005) Engagement of CD44 modulates cyclooxygenase induction, VEGF generation, and proliferation in human vascular endothelial cells. Faseb J 19 : 446-448.

63. Singleton PA, Dudek SM, Ma SF, Garcia JG (2006) Transactivation of sphingosine 1-phosphate receptors is essential for vascular barrier regulation. Novel role for hyaluronan and CD44 receptor family. J Biol Chem 281 : 34381 34393.

64. Singleton PA, Mirzapoiazova T, Guo Y, Sammani S, Mambetsariev N, et al (2010) High-molecular-weight hyaluronan is a novel inhibitor of pulmonary vascular leakiness. Am J Physiol Lung Cell Mol Physiol 299 : 639-651.

65. Deed R, Rooney P, Kumar P, Norton J D, Smith J, et al. (1997) Early-response gene signalling is induced by angiogenic oligosaccharides of hyaluronan in endothelial cells. Inhibition by non-angiogenic, high-molecular-weigh hyaluronan. Int J Cancer $71: 251-256$.

66. Horton MR, McKee CM, Bao C, Liao F, Farber JM, et al. (1998) Hyaluronan fragments synergize with interferon-gamma to induce the $\mathrm{C}-\mathrm{X}-\mathrm{C}$ chemokines mig and interferon-inducible protein-10 in mouse macrophages. $J$ Biol Chem $273: 35088-35094$

67. Horton MR, Olman MA, Bao C, White KE, Choi AM, et al. (2000) Regulation of plasminogen activator inhibitor-1 and urokinase by hyaluronan fragments in mouse macrophages. Am J Physiol Lung Cell Mol Physiol 279 : 707-715. 
68. Jiang D, Liang J, Fan J, Yu S, Chen S, et al. (2005) Regulation of lung injury and repair by Toll-like receptors and hyaluronan. Nat Med 11 : 1173-1179.

69. McKee CM, Penno MB, Cowman M, Burdick MD, Strieter RM, et al. (1996) Hyaluronan (HA) fragments induce chemokine gene expression in alveolar macrophages. The role of HA size and CD44. J Clin Invest 98 : 2403-2413.

70. Matute-Bello G, Frevert CW, Martin TR (2008) Animal models of acute lung injury. Am J Physiol Lung Cell Mol Physiol 295 : 379-399.

71. Lokeshwar VB, Selzer MG (2000) Differences in hyaluronic acid-mediated functions and signaling in arterial, microvessel, and vein-derived human endothelial cells. J Biol Chem $275: 27641-27649$.

72. Singleton PA, Bourguignon LY (2002) CD44v10 interaction with Rho-kinase (ROK) activates inositol 1,4,5-triphosphate (IP3) receptor-mediated Ca2+ signaling during hyaluronan (HA)-induced endothelial cell migration. Cell Motil Cytoskeleton $53: 293-316$.

73. Singleton PA, Bourguignon LY (2004) CD44 interaction with ankyrin and IP3 receptor in lipid rafts promotes hyaluronan-mediated $\mathrm{Ca} 2+$ signaling leading to nitric oxide production and endothelial cell adhesion and proliferation. Exp Cell Res 295 : 102-118.

74. Turley EA, Noble PW, Bourguignon LY (2002) Signaling properties of hyaluronan receptors. J Biol Chem 277 : 4589-4592.

75. Fitzgerald KA, O'Neill LA (1999) Characterization of CD44 induction by IL-1: a critical role for Egr-1. J Immunol 162 : 4920-4927.

76. Gee K, Lim W, Ma W, Nandan D, Diaz-Mitoma F, et al. (2002) Differential regulation of CD44 expression by lipopolysaccharide (LPS) and TNF-alpha in human monocytic cells: distinct involvement of c-Jun N-terminal kinase in LPSinduced CD44 expression. J Immunol 169 : 5660-5672.

77. Griffioen AW, Coenen MJ, Damen CA, Hellwig SM, van Weering DH, et al. (1997) CD44 is involved in tumor angiogenesis; an activation antigen on human endothelial cells. Blood 90 : 1150-1159.

78. Morrison H, Sherman LS, Legg J, Banine F, Isacke C, et al. (2001) The NF2 tumor suppressor gene product, merlin, mediates contact inhibition of growth through interactions with CD44. Genes Dev 15 : 968-980.

79. Oliferenko S, Kaverina I, Small JV, Huber LA (2000) Hyaluronic acid (HA) binding to CD44 activates Rac1 and induces lamellipodia outgrowth J Cell Biol $148: 1159-1164$.

80. Teder P, Heldin P (1997) Mechanism of impaired local hyaluronan turnover in bleomycin-induced lung injury in rat. Am J Respir Cell Mol Biol 17 : 376-385.

81. Teder P, Vandivier RW, Jiang D, Liang J, Cohn L, et al. (2002) Resolution of lung inflammation by CD44. Science $296: 155-158$.

82. Svee K, White J, Vaillant $P$, Jessurun J, Roongta U, et al. (1996) Acute lung injury fibroblast migration and invasion of a fibrin matrix is mediated by CD44. J Clin Invest 98 : 1713-1727.

83. Bannerman DD, Goldblum SE (1999) Direct effects of endotoxin on the endothelium: barrier function and injury. Lab Invest 79 : 1181-1199.

84. Hollingsworth JW, Li Z, Brass DM, Garantziotis S, Timberlake SH, et al. (2007) CD44 regulates macrophage recruitment to the lung in lipopolysaccharideinduced airway disease. Am J Respir Cell Mol Biol $37: 248-253$

85. Singleton PA, Salgia R, Moreno-Vinasco L, Moitra J, Sammani S, et al. (2007) CD44 regulates hepatocyte growth factor-mediated vascular integrity. Role of c-Met, Tiam1/Rac1, dynamin 2, and cortactin. J Biol Chem 282 : 30643-30657.

86. Summah H, Qu JM (2009) Biomarkers: a definite plus in pneumonia. Mediators Inflamm 2009: 675753 .

87. Ware LB (2009) Clinical year in review I: Interstitial lung disease, pulmonary vascular disease, pulmonary infections, and cardiopulmonary exercise testing and pulmonary rehabilitation. Proc Am Thorac Soc 6: 487-493.

88. Katoh S, Taniguchi H, Matsubara Y, Matsumoto N, Fukushima K, et al. (1999) Overexpression of CD44 on alveolar eosinophils with high concentrations of soluble CD44 in bronchoalveolar lavage fluid in patients with eosinophilic pneumonia. Allergy 54: 1286-1292.

89. Altemeier WA, Sinclair SE (2007) Hyperoxia in the intensive care unit: why more is not always better. Curr Opin Crit Care 13: 73-78.

90. Windt GJ, Schouten M, Zeerleder S, Florquin S, Poll T (2011) CD44 is protective during hyperoxia-induced lung injury. Am J Respir Cell Mol Biol 44: 377-383.
91. Zhao H, Leu SW, Shi L, Dedaj R, Zhao G, et al. (2010) TLR4 is a negative regulator in noninfectious lung inflammation. J Immunol 184: 5308-5314.

92. Luscher TF, Barton M (1997) Biology of the endothelium. Clin Cardiol 20: II3-10.

93. Guan H, Nagarkatti PS, Nagarkatti M (2007) Blockade of hyaluronan inhibits IL-2-induced vascular leak syndrome and maintains effectiveness of IL-2 treatment for metastatic melanoma. J Immunol 179: 3715-3723.

94. Mustafa A, McKallip RJ, Fisher M, Duncan R, Nagarkatti PS, et al. (2002) Regulation of interleukin-2-induced vascular leak syndrome by targeting CD44 using hyaluronic acid and anti-CD44 antibodies. J Immunother 25: 476-488.

95. Choi-Miura NH, Tobe T, Sumiya J, Nakano Y, Sano Y, et al. (1996) Purification and characterization of a novel hyaluronan-binding protein (PHBP) from human plasma: it has three EGF, a kringle and a serine protease domain, similar to hepatocyte growth factor activator. J Biochem 119: 1157-1165.

96. Etscheid M, Kress J, Seitz R, Dodt J (2008) The hyaluronic acid-binding protease: a novel vascular and inflammatory mediator? Int Immunopharmacol 8: 166-170.

97. Kanse SM, Parahuleva M, Muhl L, Kemkes-Matthes B, Sedding D, et al. (2008) Factor VII-activating protease (FSAP): vascular functions and role in atherosclerosis. Thromb Haemost 99: 286-289.

98. Romisch J (2002) Factor VII activating protease (FSAP): a novel protease in hemostasis. Biol Chem 383: 1119-1124.

99. Kannemeier C, Feussner A, Stohr HA, Weisse J, Preissner KT, et al. (2001) Factor VII and single-chain plasminogen activator-activating protease: activation and autoactivation of the proenzyme. Eur J Biochem 268: 3789-3796.

100. Mambetsariev N, Mirzapoiazova T, Mambetsariev B, Sammani S, Lennon FE, et al. (2010) Hyaluronic Acid binding protein 2 is a novel regulator of vascular integrity. Arterioscler Thromb Vasc Biol 30: 483-490.

101. Wygrecka M, Markart P, Fink L, Guenther A, Preissner KT (2007) Raised protein levels and altered cellular expression of factor VII activating protease (FSAP) in the lungs of patients with acute respiratory distress syndrome (ARDS). Thorax 62: 880-888.

102. Opitz B, van Laak V, Eitel J, Suttorp N (2010) Innate immune recognition in infectious and noninfectious diseases of the lung. Am J Respir Crit Care Med 181: 1294-1309.

103. Gay NJ, Gangloff M (2007) Structure and function of Toll receptors and their ligands. Annu Rev Biochem 76: 141-165.

104. Chen K, Huang J, Gong W, Iribarren P, Dunlop NM, et al. (2007) Toll-like receptors in inflammation, infection and cancer. Int Immunopharmacol 7: 1271-1285.

105. Jiang D, Liang J, Li Y, Noble PW (2006) The role of Toll-like receptors in noninfectious lung injury. Cell Res 16: 693-701.

106. Taylor KR, Yamasaki K, Radek KA, Di Nardo A, Goodarzi H, et al. (2007) Recognition of hyaluronan released in sterile injury involves a unique receptor complex dependent on Toll-like receptor 4, CD44, and MD-2. J Biol Chem 282: 18265-18275.

107. Freudenberg MA, Tchaptchet S, Keck S, Fejer G, Huber M, et al. (2008) Lipopolysaccharide sensing an important factor in the innate immune response to Gram-negative bacterial infections: benefits and hazards of LPS hypersensitivity. Immunobiology 213: 193-203.

108. Lu YC, Yeh WC, Ohashi PS (2008) LPS/TLR4 signal transduction pathway. Cytokine 42: 145-151.

109. Smith LS, Kajikawa O, Elson G, Wick M, Mongovin S, et al. (2008) Effect of Toll-like receptor 4 blockade on pulmonary inflammation caused by mechanical ventilation and bacterial endotoxin. Exp Lung Res 34: 225-243.

110. Hollingsworth JW, Cook DN, Brass DM, Walker JK, Morgan DL, et al. (2004) The role of Toll-like receptor 4 in environmental airway injury in mice. Am J Respir Crit Care Med 170: 126-132.

111. Arbour NC, Lorenz E, Schutte BC, Zabner J, Kline JN, et al. (2000) TLR4 mutations are associated with endotoxin hyporesponsiveness in humans. Nat Genet 25: 187-191.

112. Muto J, Yamasaki K, Taylor KR, Gallo RL (2009) Engagement of CD44 by hyaluronan suppresses TLR4 signaling and the septic response to LPS. Mol Immunol 47: 449-456. 
113. Scheibner KA, Lutz MA, Boodoo S, Fenton MJ, Powell JD, et al. (2006) Hyaluronan fragments act as an endogenous danger signal by engaging TLR2. J Immunol 177: 1272-1281.

114. Zaman A, Cui Z, Foley JP, Zhao H, Grimm PC, et al. (2005) Expression and role of the hyaluronan receptor RHAMM in inflammation after bleomycin injury. Am J Respir Cell Mol Biol 33: 447-454.

115. Cantor JO (2007) Potential therapeutic applications of hyaluronan in the lung Int J Chron Obstruct Pulmon Dis 2: 283-288.

116. Gaffney J, Matou-Nasri S, Grau-Olivares M, Slevin M (2010) Therapeutic applications of hyaluronan. Mol Biosyst 6: 437-443.

117. Bollyky PL, Falk BA, Wu RP, Buckner JH, Wight TN, et al. (2009) Intact extracellular matrix and the maintenance of immune tolerance: high molecular weight hyaluronan promotes persistence of induced CD4+CD25+ regulatory $T$ cells. J Leukoc Biol 86: 567-572.

118. Miki Y, Teramura T, Tomiyama T, Onodera Y, Matsuoka T, et al. (2010) Hyaluronan reversed proteoglycan synthesis inhibited by mechanical stress: possible involvement of antioxidant effect. Inflamm Res 59: 471-477.

119. Yasuda T (2007) Hyaluronan inhibits cytokine production by lipopolysaccharidestimulated U937 macrophages through down-regulation of NF-kappaB via ICAM-1. Inflamm Res 56: 246-253.

120. Garantziotis S, Li Z, Potts EN, Lindsey JY, Stober VP, et al. (2010) TLR4 is necessary for hyaluronan-mediated airway hyperresponsiveness after ozone inhalation. Am J Respir Crit Care Med 181: 666-675.

121. Henry CB, Duling BR (1999) Permeation of the luminal capillary glycocalyx is determined by hyaluronan. Am J Physiol 277: H508-H514.
122. Rubio-Gayosso I, Platts SH, Duling BR (2006) Reactive oxygen species mediate modification of glycocalyx during ischemia-reperfusion injury. Am J Physiol Heart Circ Physiol 290: H2247-H2256.

123. Nadkarni PP, Kulkarni GS, Cerreta JM, Ma S, Cantor JO (2005) Dichotomous effect of aerosolized hyaluronan in a hamster model of endotoxin-induced lung injury. Exp Lung Res 31: 807-818.

124. Liu YY, Lee CH, Dedaj R, Zhao H, Mrabat H, et al. (2008) High-molecularweight hyaluronan--a possible new treatment for sepsis-induced lung injury: preclinical study in mechanically ventilated rats. Crit Care 12: R102.

125. Churg A, Zhou S, Wang X, Wang R, Wright JL (2009) The role of interleukin1 beta in murine cigarette smoke-induced emphysema and small airway remodeling. Am J Respir Cell Mol Biol 40: 482-490.

126. Cantor JO, Cerreta JM, Ochoa M, Ma S, Liu M, et al. (2011) Therapeutic effects of hyaluronan on smoke-induced elastic fiber injury: does delayed treatment affect efficacy? Lung 189: 51-56.

127. Cantor JO, Turino GM (2004) Can exogenously administered hyaluronan improve respiratory function in patients with pulmonary emphysema? Chest 125: $288-292$

128. Devaney J, Contreras M, Laffey JG (2011) Clinical review: gene-based therapies for ALI/ARDS: where are we now? Crit Care 15: 224

129. Li Z, Potts-Kant EN, Garantziotis S, Foster WM, Hollingsworth JW (2011) Hyaluronan Signaling during Ozone-Induced Lung Injury Requires TLR4 MyD88, and TIRAP. PLoS One 6: e27137.

130. Qureshi ST, Zhang X, Aberg E, Bousette N, Giaid A, et al. (2006) Inducible activation of TLR4 confers resistance to hyperoxia-induced pulmonary apoptosis. J Immunol 176: 4950-4958.
This article was originally published in a special issue, Lung Disorders/Injury handled by Editor(s). Dr. Yutong Zhao, University of Pittsburgh, USA 